\title{
Storytelling em plataforma impressa e digital: contribuição potencial do jornalismo literário
}

Storytelling on a printed and digital platform: potential contribution of literary journalism

Storytelling en plataforma impresa y digital: contribución potencial del periodismo literario

Edvaldo Pereira Lima

- Pós-doutor em Educação pela Universidade de Toronto, Canadá

- Doutor e mestre em Ciências da Comunicação pela Escola de Comunicações e Artes da Universidade de São Paulo (ECA-USP)

- Professor aposentado do Departamento de Jornalismo e Editoração da ECA-USP

- Professor visitante de universidades do exterior (Londres e Florença - 2005; Universidad EAN, Bogotá - 2012-2014; Universidad de Antioquia, Medellín, Colômbia - 2014)

- Graduado em Turismo pela Universidade Anhembi-Morumbi e em Jornalismo pela Universidade Metodista de São Paulo (Umesp)

- Escritor, com dez livros publicados

- Diretor da EPL - Educação, Comunicação e Desenvolvimento Humano Ltda.

- E-mail: edvaldopl@terra.com.br 


\section{Resumo}

Cresceemcomunicação organizacionalaadoção depráticas de storytelling,masseuestágioaindainicial convidaacontribuições para seu aperfeiçoamento de qualidade. Este texto traz a sugestão de incorporação de elementos provenientes do jornalismo literário, notadamente a técnica da cena e a humanização de narrativas em plataformas impressas e digitais. Enfatizam-se os casos de jornais e revistas organizacionais, narrativas de memória institucional e relatórios de sustentabilidade.

\section{PALAVCRAS-CHAVE: STORYTELLING・JORNALISMO LITERÁRIO•CENA・HUMANIZACC̃̃O.}

\section{Abstract}

Storytelling is inscreasing in corporate communication, but its initial stage still invites in contributions to improve it. This article suggests the introduction of literary journalism elements, specially the scene technique and the placement of narrative focus on real life protagonists, aimed at print and digital outlets. The cases of corporate newspapers and magazines, institutional history stories and sustainability reports are pointed out.

\section{KEYWORDS: STORYTELLING・LITERARY JOURNALISM・SCENE・HUMANIZATION.}

\section{Resumo}

El uso del storytellingestá en crecimiento en comunicación organizacional, pero su fase todavía inicial invita a contribuciones para su perfeccionamiento. En este texto se presenta la sugestión de incorporación de elementos del periodismo literario, en especial la técnica de la cena y la humanización de narrativas en plataformas gráficas y digitales. Se da atención especial a los casos de periódicos y revistas organizacionales, proyectos de memoria institucional y reportes de sustentabilidad. 
0 crescimento do interesse pelo storytelling em comunicação organizacional abre possibilidade de considerações diversificadas, fruto do estágio inicial em que ainda se encontra essa tendência, especialmente nos países sulamericanos. Há um processo de familiarização em curso. Este autor relaciona a emergência do storytelling nas organizações a uma dinâmica contextual onde o próprio sistema corporativo e a sociedade como um todo passam por um intenso processo de transformação forjado pelas múltiplas eclosões de novos valores, de novas posturas e de novas vozes que buscam participação no jogo democrático.

A visão de mundo de característica linear e simplista que está na base do pensamento corporativo - e por conseguinte da comunicação organizacional - como referência predominante já não responde eficientemente às demandas dos dias de hoje. A sociedade e as organizações sofrem as múltiplas pressões que demandam a transição para o pensamento complexo, assim como para a incorporação de abordagens sistêmicas, contextuais e integradas na gestão das empresas.

É nesse contexto onde ainda impera uma mentalidade de comunicação calcada em modelos centralizadores, verticalizados (de cima para baixo) e lineares que o storytelling se introjeta no ambiente organizacional como uma alternativa promissora. A comunicação convencional, caracterizada por estruturação e estilo seco, objetivo, transportadora de maneira velada ou não de um discurso eminentemente institucional, já não pode ser tomada como um processo universalmente válido e eficaz.

O paradigma ainda prevalecente na sociedade de um excesso de valorização do racionalismo como a única via válida de entendimento da realidade mostra-se cada vez mais limitado, inclusive no âmbito organizacional. A sociedade descobre que os seres humanos são criaturas que operam em diferentes e integrados níveis de cognição, caminhando em igualdade de importância tanto sua capacidade intelectiva, lógica e racional quanto suas habilidades emocionais e seu potencial intuitivo. A comunicação que busca eficiência precisa responder ao trânsito necessário de conteúdos por todas essas dimensões cognitivas do ser.

Quando trazemos esse raciocínio do patamar das considerações epistemológicas gerais para o território específico do processo comunicacional impresso em si, podemos encontrar nas mensagens do sistema organizacional, com facilidade, a presença da função referencial de linguagem. Se tomamos as formulações de Roman Jakobson em consideração, vemos que essa função é desempenhada com frequência, mas a poética e a expressiva (pelo menos a que se formula em primeira pessoa do singular) pouco aparecem. ${ }^{1}$

Do mesmo modo, quando examinamos as mensagens narrativas, vemos muito o formato conhecido como sumário. Tratase do texto que se estrutura em torno da informação factual objetiva, típico do formato prevalecente nos jornais diários da grande imprensa, herdado pela comunicação organizacional jornalística.

Se por um lado a preferência por recursos estilísticos dessa natureza serve a propósitos comunicacionais bem explícitos e diretos, nas mensagens em que o objetivo é motivar, ampliar compreensão, engajar a criatividade, empoderar indivíduos e grupos, a receita falha. A inadequação acontece, em primeiro lugar, por falta de tratamento pertinente da figura humana. Todo o universo organizacional gira, em última instância, em torno de pessoas. As empresas geram produtos, serviços, informação e conhecimento para as pessoas e a partir de pessoas. Precisam se comunicar com pessoas em diferentes instâncias da sociedade - no ambiente governamental, nos sistemas de fornecedores, no mercado externo, no seu próprio interior -, relacionadas direta ou indiretamente ao seu próprio mundo. Para produzir efeitos desejáveis, o processo

$\overline{1 \text { As seis funções }}$ de linguagem identificadas pelo autor estão em Linguística e comunicação (Jakobson, 2008). 
comunicativo precisa incorporar elementos qualitativos superiores, do ponto de vista narrativo. Daí o storytelling e daí a contribuição potencial do jornalismo literário.

\section{STORYTELLINGE JORNALISMO LITERÁRIO}

Modalidade diferenciada da prática jornalística, o jornalismo literário sustenta-se sobre longa tradição aperfeiçoada ao longo do tempo, nascida no mesmo período em que surgiu o formato mais convencional e disseminado de jornalismo, esse do sumário que vemos todos os dias nos jornais.

Aceita-se, no geral, que a imprensa moderna começa a surgir com a criação dos primeiros jornais de larga tiragem e das agências de notícias, especialmente nos Estados Unidos, mas também na Europa, a partir da metade do século XIX. Durante a Guerra Civil daquele país - 1861 a 1865 - a cobertura do conflito contribuiu para a expansão dos jornais como veículos de comunicação de massa, ao mesmo tempo em que deu origem a um recurso narrativo que simboliza essa predileção do texto jornalístico pelo formato informativo raso: o chamado lide, derivação da palavra inglesa lead. Trata-se da concentração dos elementos primários de uma notícia - o que, quem, quando, onde, por quê - no início da mesma. 0 sumário é o suprassumo dessa mesma tendência.

Em paralelo a essa corrente, que iria prevalecer na imprensa e também influenciar predominantemente a prática jornalística nas organizações, despontaria o jornalismo literário. Enquanto aquela - a que podemos chamar de jornalismo convencional, para facilitar a navegação do leitor por este texto - pretendia única e exclusivamente informar, o jornalismo literário já nasceu com um propósito distinto. Mais do que informar, essa modalidade procura oferecer ao leitor um mergulho sensorial na realidade. Não basta a informação seca, dita objetiva, factual. O leitor é convidado a captar na narrativa as nuances ambientais de onde o acontecimento se dá. As cores, os sons, os cheiros - se possível -, o movimento dinâmico com que as ações se dão.

\section{Humanização da narrativa}

O leitor é seduzido para realizar uma imersão - simbólica, psicológica, racional, emocional -, junto com o(a) autor(a), no mundo colocado ao seu alcance pela representação narrativa que dele faz o texto. É estimulado a captar a realidade e senti-la, porque o grande propósito condutor é dar-lhe elementos para compreender a situação abordada de uma maneira muito mais rica e infinitamente menos rasa do que o texto meramente informativo é capaz de oferecer.

Complementa 0 alcance desse propósito o fundamental princípio do jornalismo literário de estruturar suas narrativas essencialmente em torno das figuras humanas colocadas no texto com o máximo de fidelidade possível à complexidade real que caracteriza cada indivíduo humano. Enquanto para o jornalismo convencional as pessoas são meramente fontes de informação, para o literário elas são personagens reais, fascinantes e complexas. Busca-se a compreensão da realidade através das pessoas que a constroem e que ao mesmo tempo são sujeitas às peculiaridades de sua totalidade. 0 conceito implícito associado é de história imediata, do fazer que caracteriza um tempo, um local, uma cultura. Aquele fazer que do hoje caminha para o amanhã e resulta do ontem.

Simultaneamente, o conceito de tempo que governa a ação do jornalismo literário é absolutamente elástico. Enquanto no jornalismo convencional o elemento temporal que guia as ações é a atualidade, no literário o tempo que serve é a 
contemporaneidade. O literário vê uma ligação importante entre os fatos de hoje e o seu desenvolver por um longo período de tempo, muitas vezes.

Da mesma maneira, o literário não se limita ao fato concreto e material que dá base às notícias - a notícia é o elemento primário e essencial que traduz um acontecimento social presente e constitui a razão de ser do jornalismo informativo convencional-, procurando transcender essa esfera reducionista para encontrá-la envolvida por outros fatores que a condicionam. Por isso, o literário tende a não ficar preso aos fatos objetivos. Procura igualmente apreender a atmosfera psicológica e a reverberação emocional que dá sentido a um acontecimento, a uma situação, a um estado de coisas que é foco de sua abordagem.

O foco mais amplo do jornalismo literário e os sentidos abertos também para as dimensões sutis e concomitantes com os quais o(a) autor (a) trabalha oferecem ao leitor um quadro abrangente da realidade. Por tudo isso e pela maestria sensível com que se trabalha as pessoas nas narrativas, o bom texto de jornalismo literário é capaz de gerar no leitor fenômenos de projeção e identificação que o fazem absorver os textos com grande intensidade compreensiva.

O segredo supremo do jornalismo literário está aliado à milenar arte de se contar história. A seu modo, porém, adaptada para um contexto contemporâneo culturalmente sofisticado. 0 arsenal de princípios, técnicas e procedimentos do jornalismo literário, formatado ao longo do tempo, maturado pela experiência, adaptado às configurações sociais de diferentes épocas e lugares, contém um know how próprio comprovado de distintas maneiras, mas cujas raízes procedem da mesma fonte que dá sustentação às narrativas míticas de todas as culturas, aos contos de fadas de todos os povos, à excelência clássica do teatro grego, ao sucesso da melhor literatura de prosa, ao êxito de bilheteria de um bom filme moderno, à popularidade de uma ótima telenovela, ao ato carinhoso da mãe contando algo ao ninar seu bebê para dormir.

Contar e ouvir, ler e escrever histórias fazem parte intrínseca da nossa natureza como seres sociais. São elementos constituintes poderosos das civilizações, são o que nos dá identidade e sentido, tornando o mundo menos caótico para nossa consciência. Estão na base da organização dos povos e dos grandes movimentos religiosos, marcam presença nos grandes livros sagrados, habitam as lendas de povos nativos, frequentam as conversas de corredor e cafezinho nas empresas, particularmente na segunda-feira após o fim de semana do qual muitos saem com novidades estimulantes para contar aos colegas de trabalho.

Contar história: unir ações desencadeadas dinamicamente no tempo, em locais específicos, envolvendo personagens determinados, desenvolvendo conflitos, provocando - se possível - catarse, iluminando nossa condição humana e o drama coletivo da existência da espécie neste planeta, nesta e noutras civilizações, em todos os tempos. 0 jornalismo literário absorve a matriz desse bem universal coletivo, utiliza-a conforme seus sofisticados recursos modernos de representação do real, extraídos de seu próprio desenvolvimento no tempo, assim como da incorporação de ferramentas intelectuais procedentes de campos como a literatura, a sociologia, a psicologia, a história.

\section{Sumário versus cena}

Em lugar do sumário, o jornalismo literário tem como instrumento narrativo preferencial a cena. Como o nome sugere, sua característica sensória é visual e cinestésica. Faz sentido, quando se nota que o propósito da modalidade é conduzir o leitor simbolicamente para dentro dos ambientes que suas narrativas representam. 
Cobrindo todas as áreas da atividade humana, inclusive economia, o jornalismo literário pode se dar - e ao leitor - o prazer da cena, como nesse trecho reproduzido por Ken Wells (2002) de uma matéria do prestigioso periódico especializado norteamericano The Wall Street Journal, assinada por John Huey (2002, p. 127-128), sobre o magnata do complexo empresarial Coca-Cola, em tradução livre do autor deste artigo:

\begin{abstract}
Auxiliares ajudam o patrão a subir na carruagem e sentar-se no macio banco de couro, onde ele veste um roupão de banho, acende um charuto e assobia chamando seu cão Labrador, Bobo, para juntar-se a ele. A carruagem, com suas quatro rodas de aros vermelhos, rádio AM e FM, tanque de água e caixa refrigeradora Coca-Cola, lidera o caminho, seguida dos caçadores e de duas vans.
\end{abstract}

"Eu atirava bem", o velho diz. "Passava vários dias sem errar um único tiro. Agora não consigo mais atirar, por causa dos olhos. Noventa anos podem não parecer muito, mas sou um homem danado de velho".

A caçada não é muito boa, por causa do tempo seco, mas ele insiste para que alguém atire nos pássaros, de maneira que Bobo tenha o que fazer. Finalmente, Bill Adkins, o superintendente de Ichauway, abate duas codornas, uma das quais ainda bate as asas quando Bobo a entrega nas mãos nodosas do Senhor Woodruff.

"Quantas você abateu?", ele pergunta ao Sr. Adkins.

"Duas, patrão".

"Quantas vezes você atirou?"

"Duas, patrão".

"Huuuumm", diz o patrão. "Uma delas estava viva".

Então o velho desce da carruagem, entra numa das vans e vai para casa. Quando chega, um funcionário serve-lhe uma Coca gelada.

A cena, recurso narrativo, está presente em todos os subgêneros do jornalismo literário, incluindo o perfil, que é a joia de sua coroa onde também brilham a reportagem temática, a narrativa de viagem, a matéria-retrato, o texto de memórias, o ensaio pessoal.

0 que todo esse arsenal de recursos narrativos e expertise em contar histórias consegue, além de oferecer textos que realçam o prazer de se ler boas histórias reais, transmitir conhecimento e geralmente provocar catarse nos receptores de mensagens - na mesma trilha da velha sabedoria dos gregos clássicos que no teatro sabiam muito bem o valor de se provocar catarse nos espectadores ao final de uma boa peça-, é conquistar a preferência do leitor.

\title{
JORNALISMO LITERÁRIO E COMUNICAÇÃO ORGANIZACIONAL
}

As implicações para a comunicação organizacional são paralelamente relevantes. Prevalece, em muitos casos, a herança do modelo jornalístico convencional, resultando em textos que informam mas não empolgam, muito menos motivam. Não mobilizam a adesão e participação dos leitores ou conseguem resultados pífios. É importante que as organizações revitalizem pelo menos parte do conteúdo de suas mensagens em veículos impressos e digitais, sob pena de estarem dispendendo recursos econômicos, tempo e esforços com abordagens pouco condizentes para com as necessidades crescentes do ambiente corporativo de nosso tempo. 
O modo mais apropriado e simples para as organizações incorporarem elementos de jornalismo literário em suas iniciativas comunicacionais consiste em absorver a essência do storytelling, como postura básica, e introduzir em suas mensagens narrativas o uso da técnica da cena, articuland o a mensagem em torno de figuras humanas reais, representativas da situação ou do tema que se deseja abordar.

A colocação do ser humano como catalisador de narrativas construídas sob o estilo de storytelling já acontece em casos específicos do mundo organizacional. Um exemplo sugestivo é a campanha "I am Fedex" ("Eu sou Fedex"), da multinacional norte-americana de transporte e logística FedExCorporation. Acampanha identifica-se como uma proposta de entendimento "da cultura FedEx através da nossa gente", como se apresenta num site dedicado, mediante a exibição de vídeos que contam distintas histórias de seus funcionários em todo o mundo. Ali são exibidos casos os mais variados, da colaboradora chinesa que também é campeã mundial de boxe amador à colega indiana que é dançarina de modalidade milenar de seu país, do mecânico que faz a manutenção dos veículos da empresa numa de suas maiores bases ao consultor de tecnologia que enfrentando deficiências visuais cria soluções customizadas de informática para clientes da empresa. ${ }^{2}$

Iniciativas como essa podem inspirar outras. Especialmente, este autor aponta a possibilidade de aperfeiçoamento das práticas de storytelling, mediante a introdução dos elementos de jornalismo literário destacados neste artigo, nos casos que se abordam na sequência.

\section{Jornais e revistas empresariais}

Tanto os veículos impressos e digitais, quanto os destinados a públicos internos ou externos ou mistos podem se beneficiar de técnicas narrativas como a cena e de procedimentos de construção das matérias centradas em personagens reais. Este autor considera lamentável que investimentos são feitos mas pouco aproveitados, em razão da insistência conservadora, em muitos casos, de as empresas manterem em seus veículos uma linha narrativa de qualidade pobre e pouca capacidade de mobilização do interesse do leitor por demasiado apego ao modo referencial burocrático de condução dos textos ou ao discurso exageradamente institucional.

\section{Mensagens de memória institucional}

Igualmente, é visão deste autor que matérias ligadas à memória institucional - publicadas nos veículos organizacionais, ou mesmo em projetos especiais em formato de livro, por exemplo - desperdiçam esforços quando são produzidas sob um enfoque demasiadamente corporativo, frio e impessoal. Afinal, são as pessoas que fazem a história acontecer. Tampouco produz efeito colocar pessoas em evidência nessas matérias mas tratá-las narrativamente com uma linguagem excessivamente dominada pela postura engessadora do sumário, da função referencial de linguagem e do reducionismo aos aspectos lineares, lógicos e objetivos (isto é, voltados ao mundo externo dos sentidos) de suas histórias. As pessoas atribuem significado a suas histórias não apenas pelo nível factual dos acontecimentos com os quais estiveram envolvidas. Dão-lhes sentido pelo valor simbólico, pelo peso emocional e pelo abrigo afetivo que a elas concedem, elementos esses habitantes do mundo psíquico interno das pessoas. A narrativa precisa ser suficientemente sensível e a atitude editorial, adequadamente arejada para comportar essas nuances do nível subjetivo que vão lhe dar qualidade e função deveras relevante.

2 Ver: <www.iamfedex.com>. Acesso em: 02/03/2014 
Uma variante desse caminho consiste na adoção, pelos profissionais de comunicação organizacional, de atitudes em apoio paralelo a projetos que, mesmo fora do ambiente estritamente corporativo, contribuam para o registro de sua memória de uma maneira qualitativamente eficiente e estilisticamente elegante. Este autor pôde escrever há pouco a biografia-perfil do primeiro presidente da Azul Linhas Aéreas Brasileiras, livro lançado em abril de 2014. 0 estilo narrativo adotado é 0 de jornalismo literário. A diretoria de comunicação, marca e produto da empresa desempenhou um papel relevante em assegurar ao biografado que esse estilo de trabalho seria pertinente para a obra.

\section{Relatórios de sustentabilidade}

A crescente pressão da sociedade sobre as organizações para que assumam clara posição relativa às questões de responsabilidade social tem gerado por parte dessas a emergente tendência de oferecer satisfação às suas comunidades externas e internas através de relatórios de sustentabilidade. Por vezes, não produzem relatórios específicos isolados, mas acrescentam conteúdos relativos à sua política de sustentabilidade nos relatórios anuais convencionais.

Não há consenso nem convenção universalmente aceita com relação ao modo como esses relatórios ou seus conteúdos devam ser tratados, do ponto de vista comunicacional, embora se expanda a adoção das diretrizes estabelecidas pela Global Reporting Initiative, organização sediada em Amsterdã e com presença espalhada pelo globo. A GRI, como é mais conhecida, advoga que as organizações assumam um compromisso vital pela disseminação do desenvolvimento sustentável pelo mundo e para isso oferece sua contribuição através de iniciativas alicerçadas nos relatórios específicos do impacto econômico, ambiental e social das ações empresariais no planeta.

Louvável a iniciativa, mas, para este autor, um caminho que tende a induzir as organizações a produzir relatórios convencionais e limitados, do ponto de vista da linguagem narrativa, tornando-os escassamente eficientes, pela inadequação entre propósito, oportunidade, função potencial e meios. É que as diretrizes da GRI estão calcadas numa abordagem eminentemente quantitativa. Os indicadores que sugere são importantes e têm uma válida função no que diz respeito à gestão, pelas organizações, das questões ligadas à responsabilidade social.

0 problema, na visão deste autor, é que a abordagem puramente quantitativa e de raciocínio exclusivamente concreto e factual não basta, neste caso. Precisa ser complementada por outra abordagem, de caráter qualitativo, algo que aparentemente as empresas não andam fazendo muito, até mesmo pela inércia do transporte automático, para os relatórios de sustentabilidade, dos procedimentos lineares e convencionais dos relatórios com os quais as organizações estão muito mais historicamente familiarizadas: os relatórios financeiros anuais.

Acontece que os relatórios de sustentabilidade - ou a incorporação de seus conteúdos aos relatórios corporativos anuais - estão atrelados, em tese, à necessidade - e ao compromisso declarado - de as empresas adequarem cultura, princípios, políticas e ações às questões da responsabilidade social. Trata-se, portanto, de algo que navega pelo universo bem mais sutil e complexo das mentalidades, assim como pela necessidade imperiosa de que toda a sociedade tome consciência desse novo conceito de desenvolvimento.

Há um processo de transformação em jogo. Os relatórios de sustentabilidade precisam não apenas apresentar resultados, da maneira convencional como os relatórios corporativos financeiros tradicionalmente fazem, mas principalmente ajudar suas comunidades - internas e externas - e a sociedade como um todo, sistemicamente, a ampliar a consciência e adquirir 
conhecimento sobre algo absolutamente novo, dentro do ambiente organizacional contemporâneo. Os relatórios têm assim, intrinsecamente, uma função educativa importante a desempenhar.

Não se pode educar com eficiência, porém, do ponto de vista comunicacional, se a mensagem utilizada é fria, insonsa, reducionista, linear, rasa. Não se pode tocar a mente e o coração do receptor se a única via de linguagem é a racional e lógica. Pois o ser humano não é apenas uma criatura logicamente pensante. Imbricada com sua inteligência racional trafega a inteligência emocional. Associadas às suas dimensões racional e emocional navegam as dimensões psicológica, simbólica, arquetípica e até mesmo espiritual (não no sentido restrito das religiões partidárias, mas sim da conectividade voluntária ou não entre a consciência individual e o quadro dinâmico mais amplo da existência, como mostram avanços de ponta em campos científicos de vanguarda como a física quântica, a psicologia arquetípica, e a proposta da transdisciplinaridade, esta inclusive advogada por um nome respeitadíssimo na área dos estudos da comunicação, Edgar Morin).

Para este autor, que pôde recentemente examinar os relatórios de sustentabilidade (ou a incorporação de seus conteúdos em relatórios corporativos convencionais) de três empresas brasileiras - 0 Boticário, Natura e Embraer - e duas colombianas - Avianca e Terpel -, há visível descompasso entre a postura de sustentabilidade dessas organizações, principalmente as que ousam assumir posição efetivamente de vanguarda - 0 Boticário, Natura e Terpel -, e o tratamento narrativo dado a seus relatórios. A linguagem é no geral raquítica, quando comparada à visão grandiosa, à política de largo horizonte adotada e às ações efetivamente implementadas. A timidez da postura comunicacional não faz jus ao propósito que essas organizações assumem de efetivamente contribuírem para a transformação das mentalidades dos atores envolvidos, gerando como frutos novas posturas, novos posicionamentos, novas realizações rumo ao estabelecimento efetivo no planeta do desenvolvimento sustentável.

Faltam a esses relatórios narrativas calcadas nas características do storytelling que thes deem não apenas solidez informativa, mas especialmente sentido e significado. Falta-lhes uma linguagem que incorpore funções como a expressiva, a poética. Falta-lhes um tratamento pleno, digno e enriquecedor de figuras humanas, em torno das quais devem girar as narrativas para transportar os temas que precisam abordar. Falta-lhes a cena, no lugar da preferência inercial pelo sumário. Falta-lhes serem menos relatórios e mais narrativas que empolguem, cativem, envolvam.

\section{CONSIDERAÇÕES FINAIS}

Nesse desafio de busca de sintonia fina entre propósitos, meios e linguagem, o jornalismo literário tem o que contribuir para que a comunicação organizacional dê um salto adiante no ajuste de suas ferramentas intelectuais. Pois a missão sistêmica maior, a disseminação e implantação efetiva do desenvolvimento sustentável na civilização contemporânea, passa obrigatoriamente pelo fio da navalha decisivo de tudo. Esse fio, naturalmente, é a comunicação.

\section{REFERÊNCIAS}

HUEY, John. The waning days of Mr. Coke. In: WELLS, Ken (Ed.). Floating off the page: the best stories from The Wall Street Journal's "Middle Column". Nova York: Simon \& Schuster, 2002. 
JAKOBSON, Roman. Linguística e comunicação. São Paulo: Cultrix, 2008.

LIMA, Edvaldo Pereira. Jornalismo literário para iniciantes. São Paulo: Edusp, 2014.

Maestro de voo: Pedro Janot e Azul - uma vida em desafios. Barueri, SP: Manole, 2014.

Páginas ampliadas. o livro-reportagem como extensão do jornalismo e da literatura/jornalismo literário. Barueri, SP: Manole, 2009.

WELLS, Ken (Ed.). Floating off the page: the best stories from The Wall Street Journal's "Middle Column". Nova York: Simon \& Schuster, 2002.

Artigo recebido em 04.03.2014 e aprovado em 16.06.2014. 